\title{
THE EFFECT OF THYMOL ON THE ELECTRICAL AND MECHANICAL ACTIVITIES OF THE GUINEA PIG ALIMENTALY CANAL
}

\author{
Yushi Ito, Takuro Osa, and Hiroshi KurIYAma \\ Department of Physiology, Faculty of Dentistry, Kyushu University, \\ Fukuoka 812, Japan
}

\begin{abstract}
Summary The effect of thymol on the electrical and mechanical activities of various regions of the guinea pig alimentary canal were investigated. 1) In the stomach, thymol $(<0.5 \mathrm{~mm})$ suppressed the generation of action potential and slow potential changes without any marked change in membrane potential and membrane resistance. Increased concentrations of thymol $(>0.5 \mathrm{~mm})$ reduced membrane potential and membrane resistance.

2) In the ileum and rectum, thymol $(<1 \mathrm{~mm})$ suppressed spike activity only without any marked change in the membrane potential. However, $1 \mathrm{~mm}$ thymol suppressed spike generation, hyperpolarized the membrane and decreased membrane resistance.

3) Thymol $(0.5 \mathrm{~mm})$ suppressed spontaneous mechanical responses which appeared in the various regions of the alimentary canal. There was no contracture except in stomach muscle.

4) Although the membrane was completely depolarized, thymol $(>1 \mathrm{~mm}$ ) suppressed the generation of phasic and tonic responses of the $\mathrm{K}$-induced contracture evoked in the various regions of the alimentary canal.

5) Topical differences of the effects of thymol on the various regions of alimentary canal were discussed in relation to the roles of $\mathrm{Ca}$ in the cells and the obtained results were compared to those observed in treatment with caffeine.
\end{abstract}

In the study of excitation-contraction coupling of guinea pig taenia coli, it was shown that caffeine directly modifies the electrical properties of the membrane (ITO and KuRIYAMA, 1971). It was also observed that caffeine blocked the slow potential changes of the pyloric region of guinea pig stomach without changing the membrane potential and electrical resistance, and in ileum caused

Received for publication April 8, 1974

伊東祐之, 長 环朗, 栗山 熙 
membrane depolarization accompanied by an increased membrane resistance and spike frequency, thus causing the elevation of muscle tone. Furthermore in rectal smooth muscle caffeine produced reduction of membrane resistance followed by membrane depolarization, the increase of spike frequencies and enhancement of muscle tone. The above results led to the conclusion that the membrane properties of the smooth muscle in alimentary canal are different from one tissue to another.

It has already been shown in skeletal muscle that thymol possesses a stronger action on the sarcoplasmic reticulum than caffeine for the release of Ca ion (OGAWA, 1970), and thymol also has a stronger and more direct action than caffeine on the plasma membrane of guinea pig taenia coli, namely it reduces the maximum rate of rise of spikes at a concentration of $0.1 \mathrm{~mm}$ and completely blocks the spike generation and mechanical response at a concentration of more than $0.5 \mathrm{~mm}$ (ITO and KuRIYAMA, 1974).

It is of interest to investigate the topical differences of thymol action on the smooth muscle activity in the various regions of the alimentary canal and to compare its effects with those of caffeine. In the present experiments the effects of thymol on the electrical and mechanical properties of stomach circular muscle and longitudinal muscles of ileum, jejunum and rectum were investigated.

\section{METHODS}

Guinea pigs of either sex, weighing 250-300 g, were stunned and bled. The stomach, ileum, jejunum, taenia coli and rectum were dissected from the abdomen (Ito and KuRIYAmA, 1974). For recording the electrical and mechanical activities, the double sucrose gap method, strain gauge and microelectrodes were used as previously described (ITO and KURIYAMA, 1974).

A Krebs solution of the following composition was used (mM); $\mathrm{NaCl}, 120.4$; $\mathrm{KCl}, 5.9 ; \mathrm{CaCl}_{2}, 2.5 ; \mathrm{NaHCO}_{3}, 15.5 ; \mathrm{MgCl}_{2}, 1.2 ; \mathrm{NaH}_{2} \mathrm{PO}_{4}, 1.2 ;$ and glucose, 11.5. For a Na-free solution, $\mathrm{NaHCO}_{3}$ and $\mathrm{NaCl}$ were omitted, and tris (hydroxymethyl) aminomethane was substituted for the $\mathrm{Na}$ ion. The $\mathrm{pH}$ of the solution was adjusted to 7.1-7.2 with $1 \mathrm{~N} \mathrm{HCl}$. When $\mathrm{Cl}$-deficient $\mathrm{Krebs}$ was used, $\mathrm{NaCl}$ and $\mathrm{KCl}$ were replaced with $\mathrm{NaNO}_{3}$ and $\mathrm{KNO}_{3}$, respectively, but $7.4 \mathrm{~mm} \mathrm{Cl}$ still remained as $\mathrm{CaCl}_{2}$ and $\mathrm{MgCl}_{2}$. Cl-deficient solutions were also prepared by replacing the $\mathrm{Cl}$ ion with either $\mathrm{Br}$ or $\mathrm{C}_{6} \mathrm{H}_{5} \mathrm{SO}_{3}$ ion.

In some experiments a modified Locke solution containing; $\mathrm{NaCl}, 154 ; \mathrm{KCl}$, 5.6; $\mathrm{CaCl}_{2}, 2.2 ; \mathrm{NaHCO}_{3}, 8.0$; and glucose, $5.5(\mathrm{~mm})$ was used as the normal physiological solution. Isotonic $\mathrm{KCl}$-Locke solution was prepared by replacing $\mathrm{NaCl}$ and $\mathrm{NaHCO}_{3}$ with isomolar $\mathrm{KCl}$ and $\mathrm{KHCO}_{3}$, respectively. To prepare the thymol solution (Thymolum, Ishizu Pharm. Co., Ltd.), ethanol was used as a solvent (Ito and KuriYAma, 1974). 


\section{RESULTS}

Effect of thymol on contractile activity

Figure 1 shows the effect of thymol $(0.5 \mathrm{~mm})$ on the mechanical activities of stomach circular muscle, longitudinal muscle of the ileum, jejunum, caecum, and

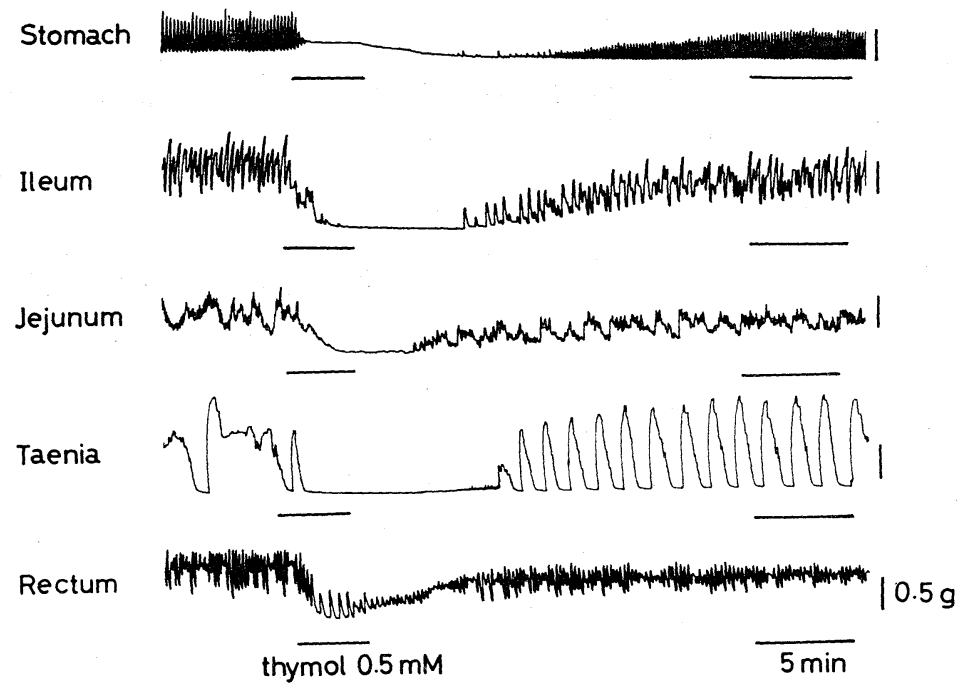

Fig. 1. Effects of thymol $(0.5 \mathrm{~mm})$ on the spontaneously generated mechanical activity. Except for stomach (circular muscle), longitudinal muscle strips were used.
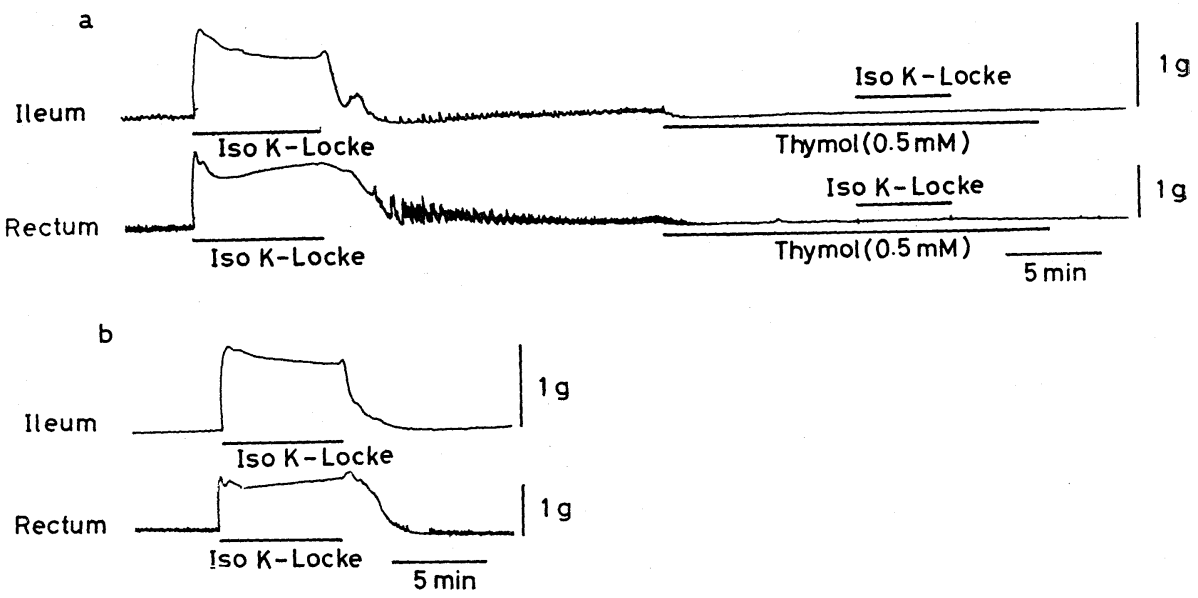

Fig. 2. Effect of isotonic K-Locke solution on the longitudinal muscles of the ileum and rectum before and during application of thymol $(0.5 \mathrm{~mm})$. a, effects of isotonic K-Locke solution before and during application of thymol. b, effects of isotonic K-Locke solution after removal of thymol. 
rectum. The tissues were continuously active in normal Krebs solution. On application of thymol $(0.5 \mathrm{mM})$ the spontaneous activity was completely inhibited and except in stomach, the muscle relaxed to resting tension level. In the circular muscle of the stomach, the spontaneous and rhythmic contractions were completely blocked by thymol and slight contracture occurred. As a consequence, the muscle further relaxed after the removal of thymol. As shown in Fig. 2, application of excess K-Locke solution (isotonic $\mathrm{K}$ ) induced phasic and tonic responses of $\mathrm{K}$-contracture in ileal and rectal smooth muscles (a). The phasic response of ileal muscle declined to a maintained tonus. In the rectum, however, the phasic component was followed by a tonic component which gradually increased and exceeded the phasic response in amplitude. After pretreatment with $0.5 \mathrm{~mm}$ thymol, the isotonic K-Locke solution could evoke neither phasic nor tonic responses of $\mathrm{K}$-contracture in either tissue. These thymol effects were reversible (b).

Figure 3 shows the effects of pretreatment with thymol on the K-contracture of stomach circular muscle observed by the double sucrose gap method. Treatment with $1 \mathrm{~mm}$ thymol reduced membrane resistance and blocked spike potential evoked by outward current pulses, excess K-Krebs solution could not evoke any tension development although the membrane was depolarized.

\section{Effects of thymol on the membrane properties of stomach circular muscle}

Figure 4 shows the effects of thymol on the resting membrane potential, slow potential changes accompanied by spike potentials and electrotonic potentials evoked by extracellularly applied inward current pulses. Inward current pulses were applied during the slow potential change intervals. At a concentration of $0.1 \mathrm{~mm}$, thymol initially reduced the amplitude and frequency of the spike superimposed on the slow potential change, and then completely blocked spike generation. At the same time thymol gradually reduced the amplitude of the slow potential changes and then completely inhibited them without any change of the membrane potential. Changes in the membrane resistance estimated from the amplitude of the electrotonic potentials was slightly reduced.

When the concentration of thymol was increased stepwise to $1 \mathrm{~mm}$, the amplitude of the electrotonic potential was reduced proportionally. For example, compared with the control value the mean values of the electrotonic potential after treatment with $0.1 \mathrm{~mm}$ and $0.5 \mathrm{~mm}$ thymol were $92.0 \%(n=10)$, and $5.5 \%$ $(n=15)$, respectively. By treatment with $0.5 \mathrm{~mm}$ thymol, the membrane potential was depolarized from $-57.8 \mathrm{mV}(n=25, \mathrm{SD}= \pm 4.4)$ to $-47.4 \mathrm{mV}(n=25, \mathrm{SD}=$ \pm 4.4 ). When the concentration of thymol was increased to $1 \mathrm{~mm}$ the membrane was further depolarized to $-44.0 \mathrm{mV}(n=25, \mathrm{SD}= \pm 2.6)$.

To investigate the ionic mechanisms involved in the effects of thymol on the membrane potential and membrane resistance, experiments were carried out in various ionic environments with microelectrodes. Various concentrations of 


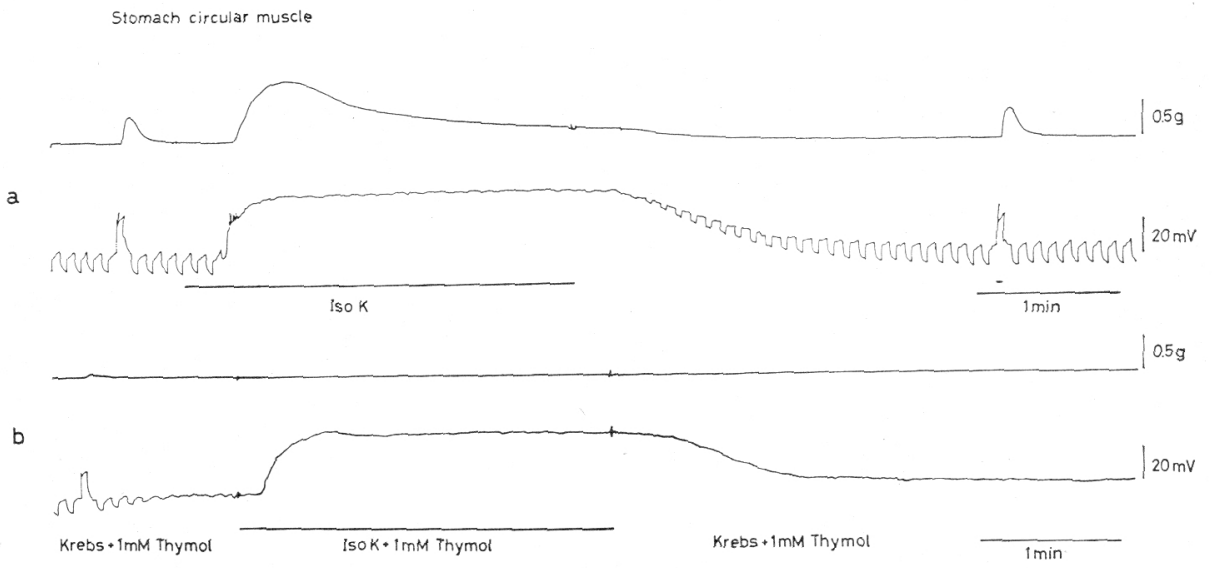

Fig. 3. Effects of isotonic K-Locke solution on the electrical and mechanical activity of the stomach before and during application of thymol $(1 \mathrm{mM})$. a, before application of thymol. b, during application of thymol. The double sucrose gap method was used. Top record is mechanical response and lower record is electrical response. Throughout the experiment, inward current pulses $\left(3 \times 10^{-7} \mathrm{~A}, 3 \mathrm{sec}\right)$ were applied. Short bars in the figure indicate the application of outward current pulses $\left(6 \times 10^{-7} \mathrm{~A} ; 3 \mathrm{sec}\right)$.

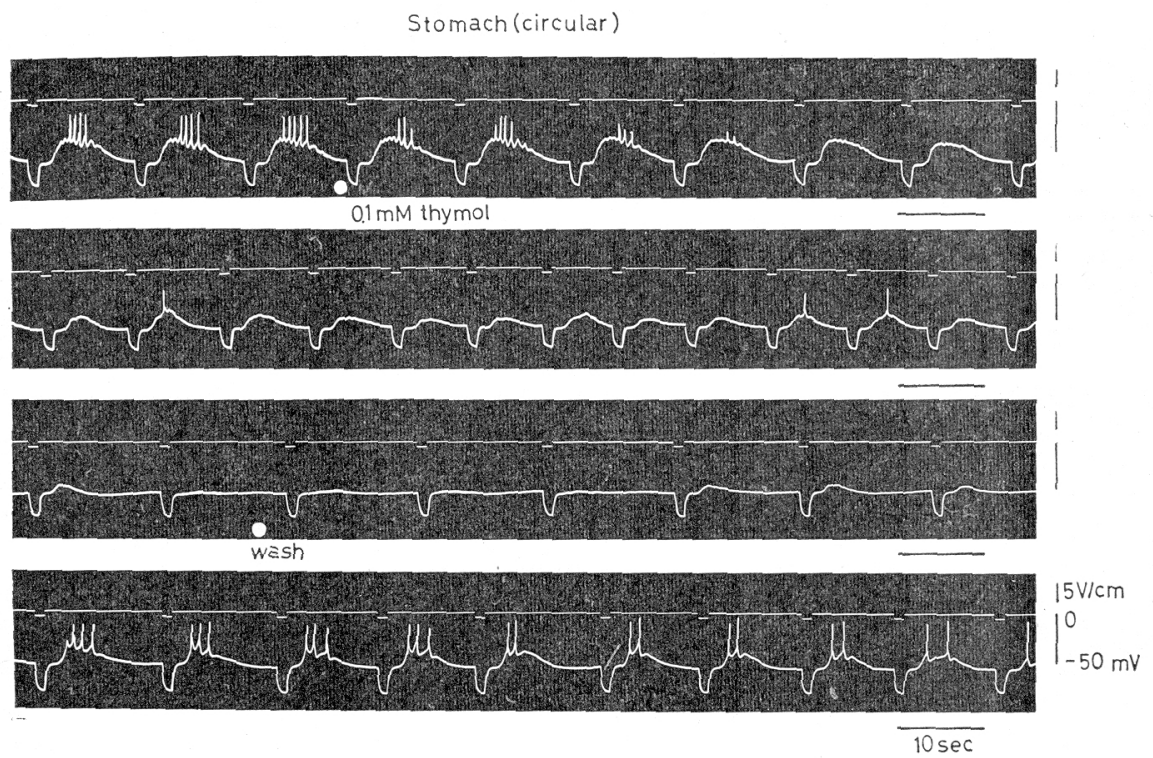

Fig. 4. Effects of thymol $(0.1 \mathrm{~mm})$ on the electrical activity of the circular muscle of stomach recorded with microelectrode. Inward current pulses were applied during the intervals between successive slow potential changes. Dots in the figure indicate the application and removal of thymol. 
thymol $(0.1 \mathrm{~mm}-1 \mathrm{~mm})$ were used to investigate the relationship between the concentration of thymol and the change of membrane resistance (relative changes in amplitude of the electrotonic potential) as well as the effect on membrane potential. The results are summarized in Fig. 8.

Effects of thymol (0.2 and $0.5 \mathrm{~mm})$ on the electrical activity of circular muscle of stomach in $\mathrm{Cl}$-deficient $\mathrm{Krebs}$ solution were of interest because it was shown in the taenia coli that thymol at a concentration of $0.5 \mathrm{~mm}$ increased the $\mathrm{Cl}$ conductance selectively (ITO and Kuriyama, 1974). In Cl-deficient $\left(\mathrm{C}_{6} \mathrm{H}_{5} \mathrm{SO}_{3}\right)$ Krebs solution, the amplitude of the slow potential changes was reduced although the frequency was much the same in normal Krebs solution, or they were completely blocked. In the experiment shown in Fig. $5(\mathrm{a}-\mathrm{c})$, slow potential changes
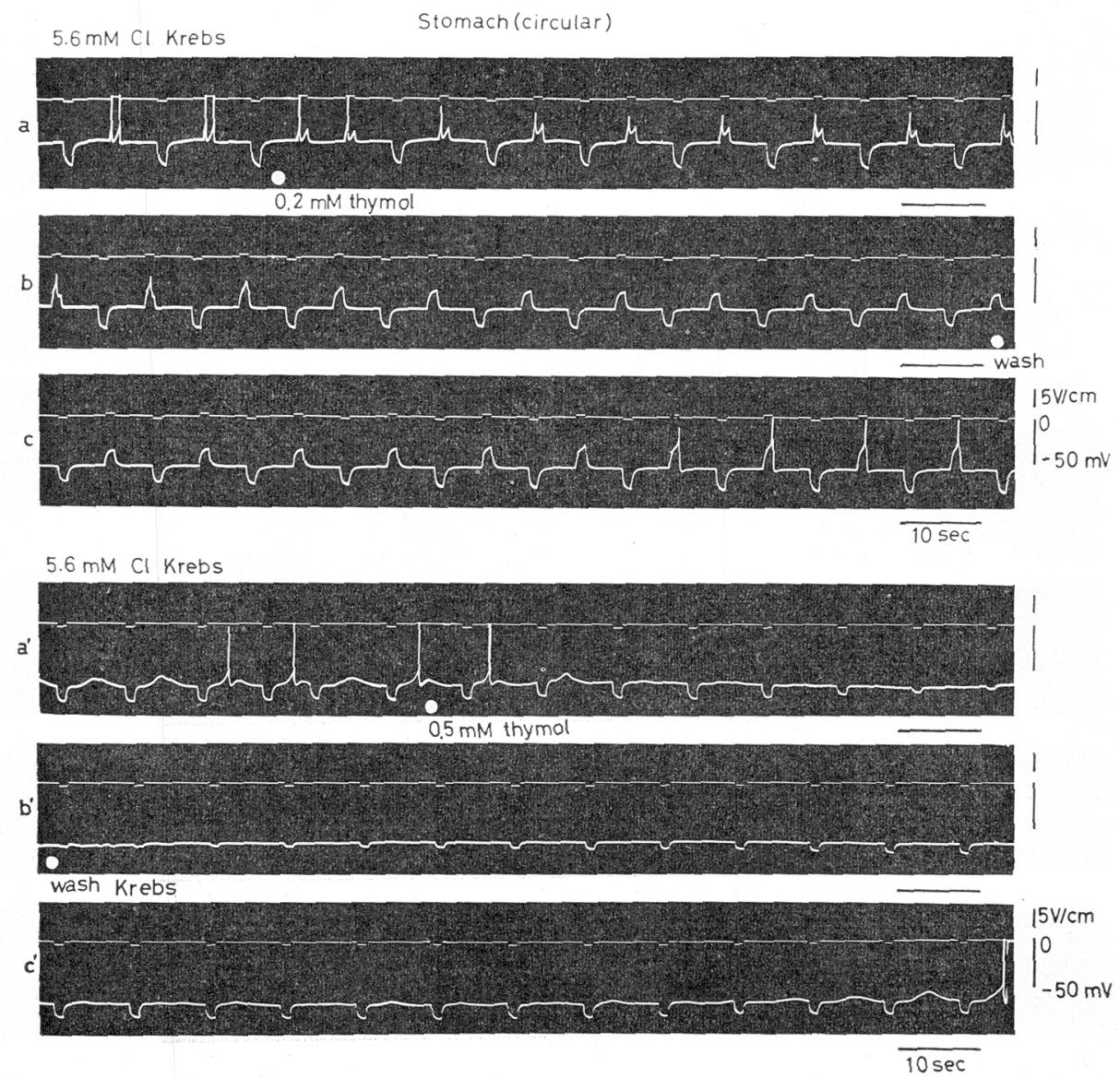

Fig. 5. Effects of thymol on the electrical activity and electrotonic potential of the stomach muscle in $\mathrm{Cl}$-deficient Krebs solution recorded with microelectrode. $\mathrm{Cl}$ in $\mathrm{NaCl}$ and $\mathrm{KCl}$ was substituted by $\mathrm{C}_{6} \mathrm{H}_{5} \mathrm{SO}_{3}$. a-c, $0.2 \mathrm{~mm}$ thymol. $\mathrm{a}^{\prime}-\mathrm{c}^{\prime}, 0.5 \mathrm{~mm}$ thymol. Dots in the figure indicate the application and removal of thymol. 
were completely blocked by treatment with Cl-deficient Krebs solution. On application of $0.2 \mathrm{~mm}$ thymol, the amplitudes of spikes and electrotonic potentials evoked by inward and outward current pulses were gradually reduced, and spike generation was completely blocked. The relative membrane resistance calculated from the electrotonic potential after treatment with $0.2 \mathrm{~mm}$ thymol against the control value was $71 \%(n=5)$, and the value in normal Krebs solution was $60 \%$ $(n=5)$. In another experiment shown in Fig. $5\left(a^{\prime}-c^{\prime}\right)$, Cl-deficient Krebs solution did not abolish completely the slow potential changes, although the amplitude was reduced to about one-fifth the normal amplitude. Spontaneous spike dis-
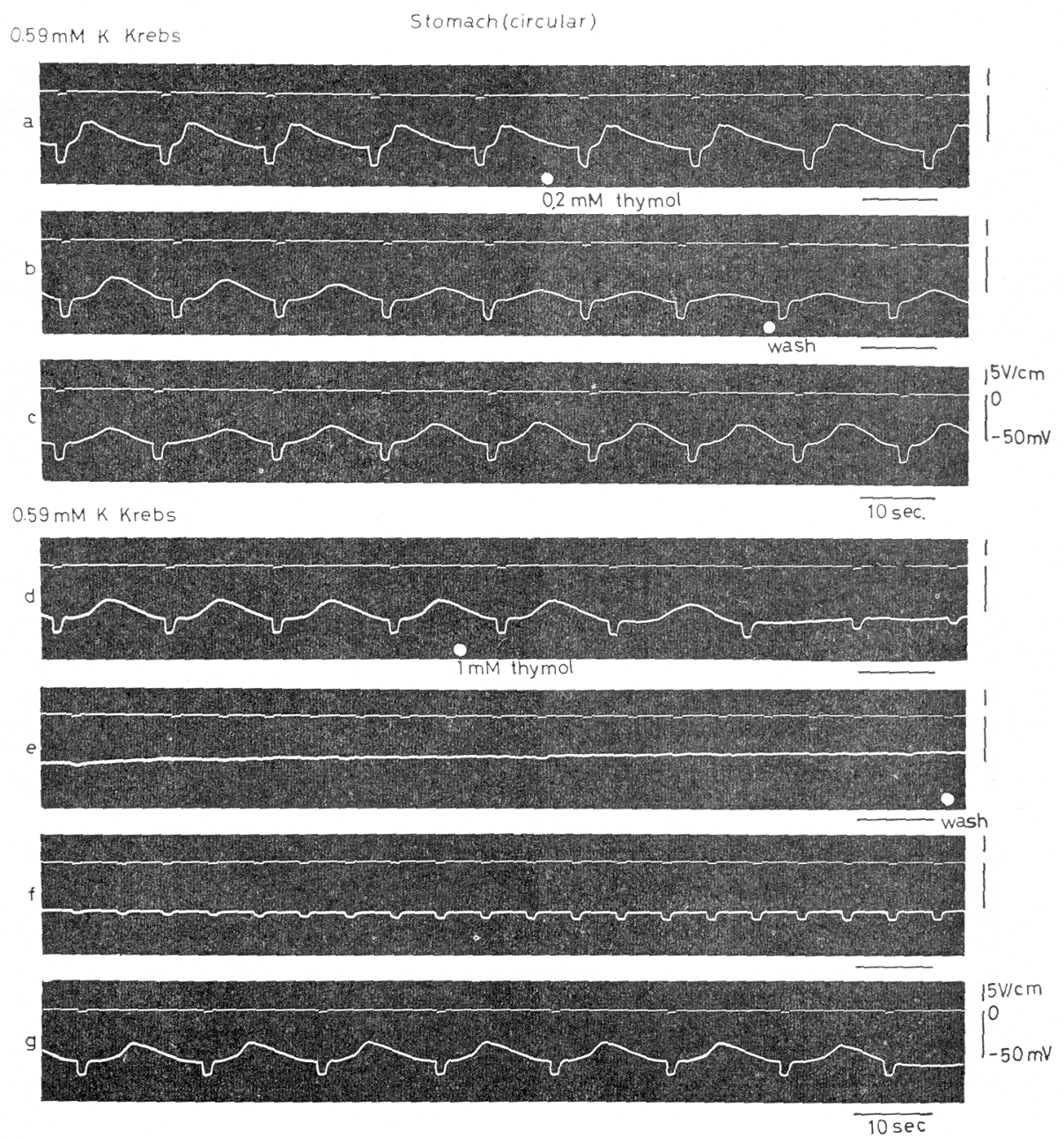

Fig. 6. Effects of thymol on the electrical activity and electrotonic potential of the stomach in $\mathrm{K}$-deficient $(0.59 \mathrm{~mm})$ Krebs solution. a-c, effects of $0.2 \mathrm{~mm}$ thymol. $\mathrm{d}$-g, effect of $1 \mathrm{~mm}$ thymol. Dots in the figure indicate the application and removal of thymol. 
charges could be observed. Thymol, at a concentration of $0.5 \mathrm{~mm}$, completely blocked the generation of spontaneous spikes and slow potential changes, and furthermore reduced the relative membrane resistance against the control value to $11.6 \%(n=8)$ without change of the resting membrane potential. When thymol was replaced with normal Krebs solution, slow potential changes and spontaneous spikes could be observed. Effects of thymol ( 0.2 and $0.5 \mathrm{~mm})$ on the relative membrane resistance and membrane potential are summerized in Fig. 8.

To investigate the effects of thymol on the membrane resistance and resting membrane potential in relation to $\mathrm{K}$ ion, the effects of thymol in $\mathrm{K}$-deficient Krebs solution (one-tenth of the normal concentration, $0.59 \mathrm{~mm}$ ) were observed (Fig. 6). In the K-deficient Krebs solution, the amplitude but not the frequency of the slow potential changes was reduced. Thymol $(0.2 \mathrm{~mm}-1 \mathrm{~mm})$ blocked the generation of slow potential change and reduced membrane resistance. The mean values of membrane resistance after treatment with 0.2 and $1 \mathrm{~mm}$ thymol against the control value in $\mathrm{K}$-deficient solution were $87.7 \%(n=10)$ and $5.0 \%(n=9)$, respectively, and those values observed in normal Krebs solution were $59 \%(n=15)$ and $2.1 \%(n=10)$, respectively. In K-deficient Krebs solution, thymol $(0.2 \mathrm{~mm})$ hyperpolarized the membrane from $-62.7 \mathrm{mV}(n=25, \mathrm{SD}= \pm 2.4)$ to $-70.1 \mathrm{mV}$ $(n=25, \mathrm{SD}= \pm 4.9)$ but $1 \mathrm{~mm}$ thymol depolarized the membrane from $-62.4 \mathrm{mV}$ $(n=24, \mathrm{SD}= \pm 1.6)$ to $-31.7 \mathrm{mV}(n=20, \mathrm{SD}= \pm 8.3)$.

Effects of thymol on the electrical properties of stomach circular muscle were observed in Na-deficient (tris) Krebs solution. In Na-deficient Krebs solution,


Fig. 7. Effects of thymol on the membrane potential and electrotonic potential recorded from the stomach circular muscle. Tissue was in Na-deficient (tris) Krebs solution. Dots in the figure indicate the application and removal of thymol $(1 \mathrm{mM})$. 
the amplitude of slow potential changes was reduced to about one-sixth of the control, but the frequency was not affected. 0.2 and $1 \mathrm{~mm}$ thymol (shown in Fig. 7) blocked the initiation of slow potential changes and reduced the relative membrane resistance to $68.5 \%(n=15)$ and $12.4 \%(n=11)$, respectively. The reduction of the membrane resistance induced by treatment with $1 \mathrm{~mm}$ thymol in Nadeficient Krebs solution was smaller than the corresponding reduction observed in normal Krebs solution respectively. Furthermore, thymol hyperpolarized the membrane in Na-deficient Krebs solution from $-55.0 \mathrm{mV}(n=20, \mathrm{SD}= \pm 3.1)$ to $-63.8 \mathrm{mV}(n=20, \mathrm{SD}= \pm 3.6)$ in $0.2 \mathrm{mM}$ thymol and from $-56.6 \mathrm{mV}(n=20$, $\mathrm{SD}= \pm 1.9)$ to $-64.8 \mathrm{mV}(n=20, \mathrm{SD}= \pm 4.3)$ in $1 \mathrm{~mm}$ thymol. The Student test shows a significant difference between the above mean values $(<0.05)$.

Effects of different concentrations of thymol on the membrane resistance and membrane potential in various ionic environments are shown diagramatically in Fig. 8. From the results obtained the effects of thymol can be summarized as follows: at a concentration of $0.2 \mathrm{~mm}$ the membrane is hyperpolarized but at $1 \mathrm{mM}$ it is depolarized in K-deficient Krebs solution; the reduction in membrane resistance produced by $0.2 \mathrm{~mm}$ thymol in similar is Na-deficient solution and the

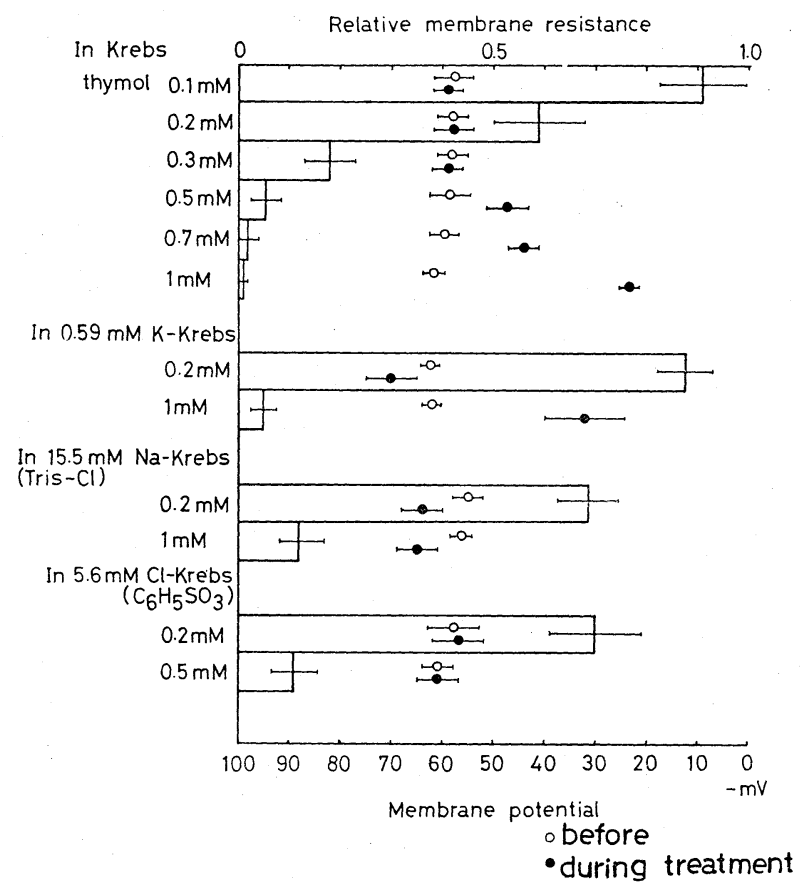

Fig. 8. Effects of various concentrations of thymol on the membrane potential and relative membrane resistance of the stomach in the various ionic environments. $\bigcirc$ and indicate the membrane potential before and during application of thymol respectively. The relative membrane resistance was a comparison of the amplitude of the electrotonic potential in the presence and absence of thymol. 
reduction in membrane resistance induced by $1 \mathrm{~mm}$ thymol was smaller in $\mathrm{Na}$ and $\mathrm{K}$-deficient Krebs solutions than in normal Krebs solution. It may therefore, be possible to conclude that at a concentration of more than $0.1 \mathrm{~mm}$, thymol suppresses the generation of slow potential changes in the stomach; at $0.2 \mathrm{~mm}$ the main effect is an increase in $\mathrm{K}$ conductance at the membrane and at $1 \mathrm{~mm}$ both $\mathrm{K}$ and $\mathrm{Na}$ conductances are increased; thymol up to $1 \mathrm{~mm}$ has no effect on $\mathrm{Cl}$ conductance.

\section{Effects of thymol on the ileum and rectum}

Effects of thymol on the electrical properties of longitudinal muscle of the ileum and rectum were observed by the microelectrode method. Figure $9(a-c)$ shows the effects of thymol on the resting membrane potential, spikes and electrotonic potentials evoked by extracellularly applied inward and outward current

Ileum



$\widetilde{10 \mathrm{sec}}$

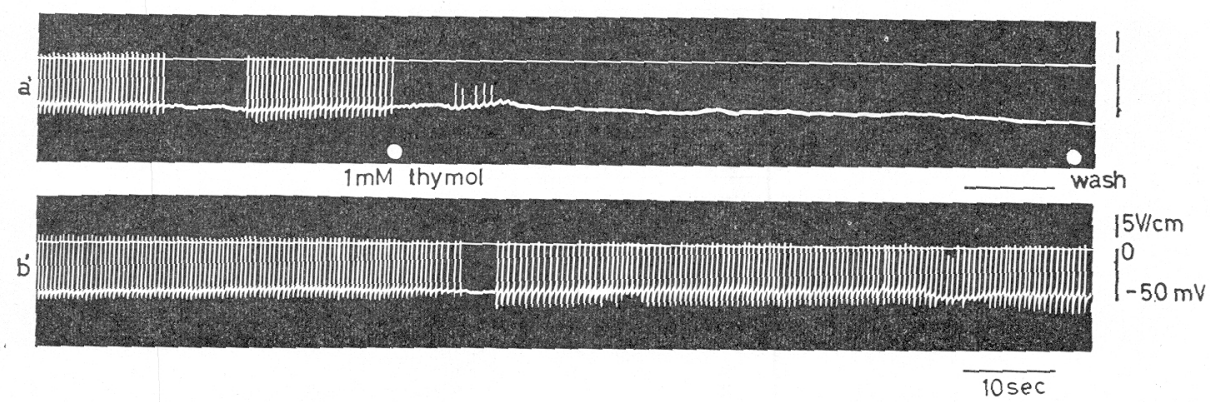

Fig. 9. Effects of thymol (1 mM) on the membrane activity and electrotonic potential of ileum smooth muscle recorded with microelectrode. a-c, effects of thymol on the evoked spike and electrotonic potential. $\mathrm{a}^{\prime}-\mathrm{b}^{\prime}$, effects of thymol on the spontaneous activity of the membrane and membrane potential. Dots in the figure indicate the application and removal of thymol. 

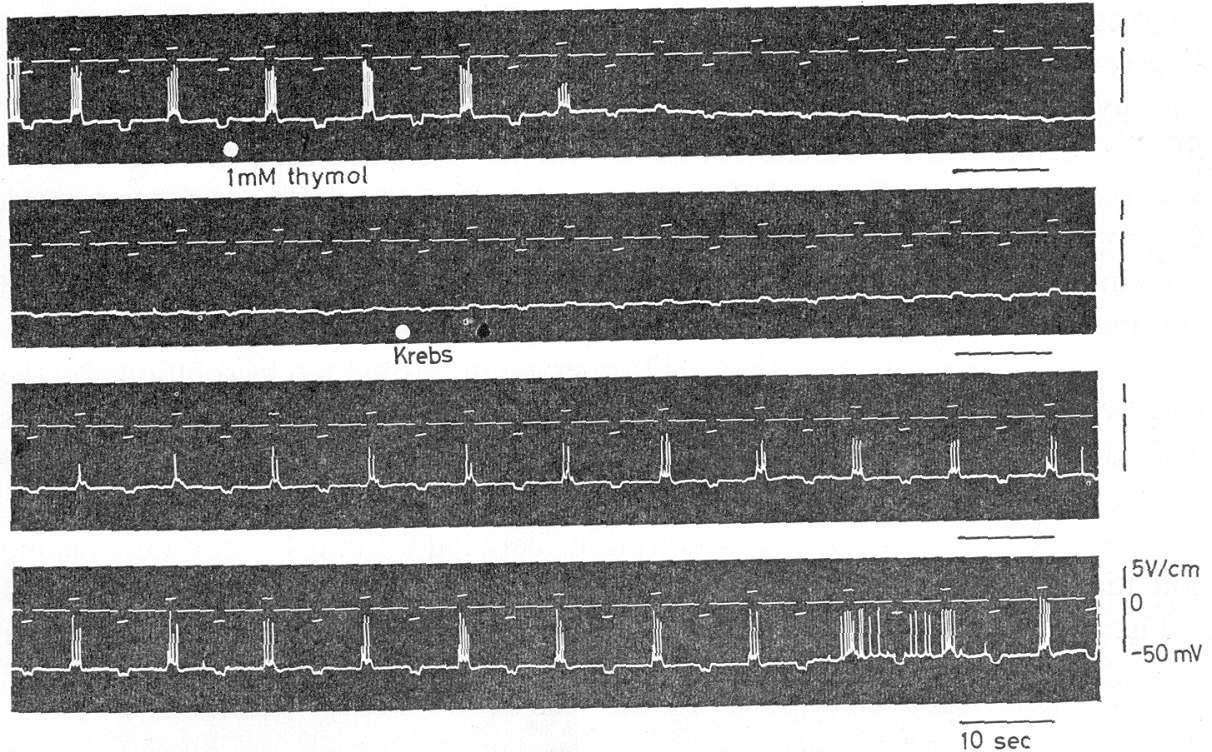

Fig. 10. Effects of thymol (1 mm) on spontaneous and evoked membrane activity, electrotonic potential and membrane potential recorded with microelectrode from the longitudinal smooth muscle of rectum. Dots in the figure indicate the application and removal of thymol.

pulses of the ileal smooth muscle. Thymol (1 mM) hyperpolarized the membrane from $-60 \mathrm{mV}$ to $-66 \mathrm{mV}$, and greatly reduced the amplitude of electrotonic potentials induced by inward current pulses. The mean value of the membrane potential before and after treatment with $1 \mathrm{~mm}$ thymol was $-56.5 \mathrm{mV}(n=15$, $\mathrm{SD}= \pm 2.1)$ and $-64.5 \mathrm{mV}(n=15, \mathrm{SD}= \pm 3.5)$, respectively, and the membrane resistance after treatment with thymol against the control value was $11.3 \%(n=4$, $\mathrm{SD}= \pm 2.1$ ). Spikes could not be evoked by any outward current pulses. Thymol also blocked the spontaneous spike discharges and then hyperpolarized the membrane as shown in Fig. $9\left(a^{\prime}-b^{\prime}\right)$.

In rectal smooth muscle, thymol ( $1 \mathrm{~mm}$ ) inhibited the spontaneous and evoked spikes, reduced the membrane resistance and hyperpolarized the membrane (Fig. 10). The mean values of the resting membrane potential in normal Krebs solution and after treatment with $1 \mathrm{~mm}$ thymol were $-55.4 \mathrm{mV}(n=20, \mathrm{SD}= \pm 3.6)$ and $-66.5 \mathrm{mV}(n=20, \mathrm{SD}= \pm 4.0)$, respectively. The mean value of the membrane resistance against the control value after treatment with $1 \mathrm{~mm}$ thymol was $25.1 \%(n=5, \mathrm{SD}= \pm 9.8)$.

To investigate the ionic mechanisms involved in the effects of thymol on the membrane potential and resistance of the rectum, the experiment was carried out 
in K-deficient Krebs solution (one-tenth the normal concentration, $0.59 \mathrm{~mm}$ ). As shown in Fig. 11, the spontaneous activity appeared as continuous spike discharges at a frequency of about 30-80/min either with (a) or without (b) afterhyperpolarization of the spike. In the $\mathrm{K}$-deficient Krebs solution, the membrane was hyperpolarized from $-55.0 \mathrm{mV}(n=20, \mathrm{SD}= \pm 3.0)$ to $-58.9 \mathrm{mV}(n=25$, $\mathrm{SD}= \pm 2.2$ ), and the frequency of the spontaneous spike discharges was reduced and the amplitude of the after-hyperpolarization of the spikes and suppressed. On application of $1 \mathrm{~mm}$ thymol, the membrane was further hyperpolarized to $-63 \mathrm{mV}(n=10, \mathrm{SD}= \pm 2.9)$, the spontaneous spike discharges were suppressed and membrane resistance was also reduced. However the reduction of the membrane resistance was smaller than that observed in normal Krebs solution, i.e. the mean values of the membrane resistance in $1 \mathrm{~mm}$ thymol against the control values in K-deficient Krebs and in normal Krebs were 38.3\% $(n=3, \mathrm{SD}= \pm 8.7)$ and $22.1 \%(n=5, \mathrm{SD}= \pm 9.8)$, respectively.

The effects of thymol, at concentrations between 0.1 and $1 \mathrm{~mm}$, on the resting potential in normal Krebs solution and K-deficient Krebs solution are summarized in Fig. 12. Thymol, at a concentration of $0.1 \mathrm{~mm}$, did not affect the membrane

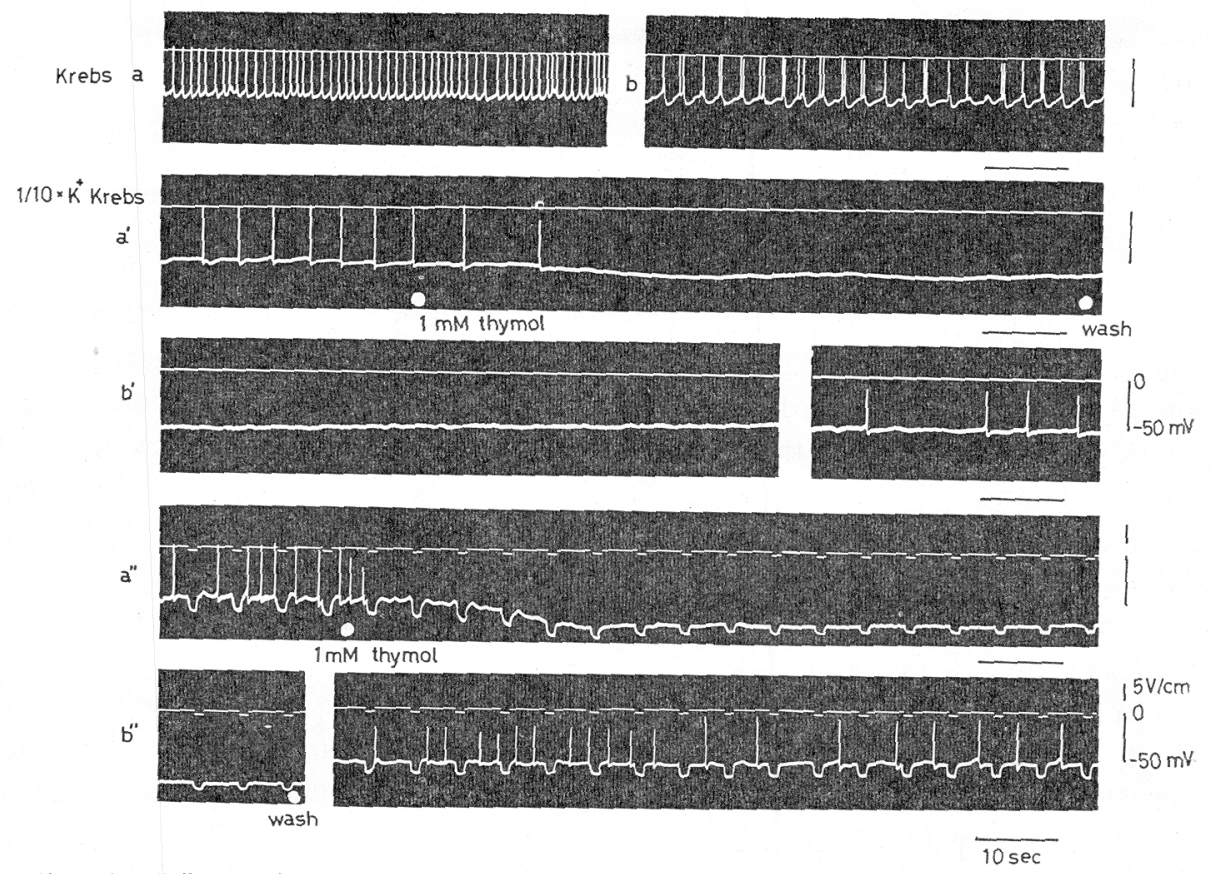

Fig. 11. Effects of thymol (1 mM) on the electrical activity, electrotonic potential and membrane potential recorded from the longitudinal muscle of rectum. a and $b$, spontaneous activity in Krebs solution. $a^{\prime}$ and $b^{\prime}$, effects of thymol on electrical activity in K-deficient Krebs solution. $a^{\prime \prime}$ and $b^{\prime \prime}$, effect of thymol on the electrotonic potential in K-deficient Krebs solution. Dots in the figure indicate the application and removal of thymol. 


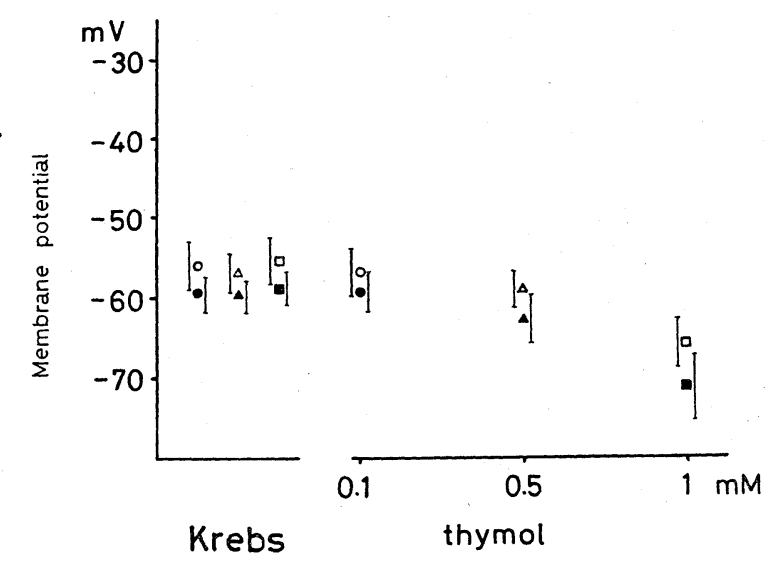

Fig. 12. Effects of various concentrations of thymol on the membrane potential in normal and in K-deficient $(0.59 \mathrm{~mm})$ Krebs solutions. $O, \triangle$, and $\square$, membrane potential in Krebs solution. $\boldsymbol{\bullet}, \mathbf{\Delta}$, and $\mathbf{m}$, membrane potential in $\mathbf{K}$-deficient Krebs solution.

potential in either the normal or K-deficient Krebs solution. Thymol (0.5 mM) hyperpolarized the membrane from $-59.0 \mathrm{mV}(n=25, \mathrm{SD}= \pm 2.1)$ to $-63.0 \mathrm{mV}$ $(n=25, \mathrm{SD}= \pm 2.9)$ in K-deficient Krebs solution, but not in normal Krebs solution. However, $1 \mathrm{~mm}$ thymol hyperpolarized the membrane in normal Krebs solution as well as in K-deficient Krebs solution. From these experiments, hyperpolarization of the membrane was more prominent in K-deficient Krebs solution than in normal Krebs solution.

\section{DISCUSSION}

In skeletal muscle it has already been shown that of the aromatic alcohols thymol most strongly inhibits the binding of $\mathrm{Ca}$ by fragmented sarcoplasmic reticulum and thus causing the enhancement of the $\mathrm{K}$-induced contracture (EBASHI, 1965; OGAWA, 1970). In smooth muscle of the guinea pig taenia coli, it is postulated that thymol does not inhibit binding but suppresses Ca-influx across the membrane and also induces immobilization of the sequestered $\mathrm{Ca}$ or removal of available Ca (ITO and KurIYAMA, 1974). The effects of thymol on the spontaneous mechanical activity of the smooth muscle cells of stomach, ileum and rectum as in taenia coli were consistently inhibitory, although in stomach thymol induced a small contracture that was maintained during the presence of the drug. The phasic and tonic responses of the $\mathrm{K}$-induced contracture were also completely inhibited by pretreatment with $0.5 \mathrm{~mm}$ thymol in stomach, ileum, taenia coli, and rectum. In the completely depolarized tissues, thymol, therefore, might suppress not only the influx of $\mathrm{Ca}$, but also release of $\mathrm{Ca}$ from sequestered sites during the $\mathrm{K}$-induced membrane depolarization in the alimentary canal. 
The effects of thymol on spike generation were consistently inhibitory in the smooth muscle cells of the alimentary canal. The mechanism is thought to be suppression of the inward current during the active state of the membrane. In smooth muscle cells, it is known that $\mathrm{Ca}$ is the ion involved in spike electrogenesis (see reviews; BÜlbring, 1962; Bülbring and TomitA, 1970; KuriYAMA, 1970). Therefore as proposed in connection with the smooth muscle cells of guinea pig taenia coli, it might be possible to explain that suppression of spike generation by thymol in stomach, ileum, and rectum is due to immobilization of $\mathrm{Ca}$ or complete removal of Ca from the membrane (ITO and KuRIYAMA, 1974).

The effects of thymol on the resting membrane potential are different from region to region in the alimentary canal. For instance thymol depolarized the membrane of stomach smooth muscle cells, hyperpolarized the ileum and rectum, and did not change the membrane potential in taenia coli. It is considered that in the stomach muscle, thymol at a concentration of $0.2 \mathrm{~mm}$ mainly increases the $\mathrm{K}$ permeability of the membrane and at $1 \mathrm{~mm}$ increases both the $\mathrm{Na}$ and $\mathrm{K}$ permeability of the membrane. Participation of $\mathrm{Cl}$ ion in the effects of thymol could be ruled out. In the ileum and rectum, thymol $(>0.5 \mathrm{~mm})$ might act mainly by increasing the $\mathrm{K}$ permeability only because thymol reduced the membrane resistance and hyperpolarized the membrane. In guinea pig taenia coli it was reported that thymol evoked an increase of $\mathrm{Cl}$ permeability which was not accompanied by a change of membrane potential (ITO and KuriYama, 1974). The decrease in membrane resistance followed by membrane depolarization induced by thymol in stomach is very similar to the membrane depolarization of taenia coli in low $\mathrm{Ca}$ solution, whereas the action of thymol on ileum and rectum resembles the effect of excess $\mathrm{Ca}$ on the taenia coli since both induce membrane hyperpolarization with decrease in membrane resistance. This therefore suggests that if thymol acts on the same site on all the smooth muscle cell membranes, whether the phospholipid or protein layer, its action may different in stomach and in intestine and may remove all available $\mathrm{Ca}$ from the membrane in stomach but produce immobilization of the sequestered $\mathrm{Ca}$ in ileum and rectum. In this respects, taenia coli is not typical of intestinal smooth muscle.

Presumably, caffeine and thymol both act on smooth muscle through modification of bound $\mathrm{Ca}$ in the membrane. It was suggested that the primary action of thymol is the immobilization or removal of sequestered $\mathrm{Ca}$. The main effect of caffeine, however, is to release Ca from these sites (Iто et al., 1974). This is reflected in the marked different effects of these drugs on the smooth muscle membranes of stomach, ileum, taenia coli, and rectum. For example, i) in stomach, thymol, at a concentration of more than $0.5 \mathrm{~mm}$, depolarized the membrane with an accompanying decrease in membrane resistance, but caffeine induced a change of neither membrane potential nor membrane conductance; although both of these drugs completely blocked the spikes and slow potentials. ii) in ileum, thymol hyperpolarized the membrane, produced a reduction in the membrane 
resistance and completely inhibited the spike generation, but caffeine induced membrane depolarization with or without a slight increase of the membrane resistance and enhanced the spike in amplitude and frequency. iii) in taenia coli, thymol (0.5-1 mM) did not change the membrane potential but markedly reduced the membrane resistance. Thymol also blocked spike generation and suppressed the mechanical response. Caffeine depolarized the membrane, reduced the membrane resistance and blocked the mechanical response. iv) in rectum, thymol induced the membrane hyperpolarization accompanied by a decrease in membrane resistance, and completely inhibited the spike generation mechanism. Caffeine, however, induced membrane depolarization and decrease of membrane resistance, and furthermore enhanced the frequency of spikes.

\section{REFERENCES}

BüLBRING, E. (1962) Electrical activity in intestinal smooth muscle. J. Physiol. Rev., 42 suppl. 5: 160-174.

BÜlbring, E. and TomitA, T. (1970) Calcium and the action potential in smooth muscle. In Calcium and Cellular Function, ed. by CuthBert, A. W. London, Macmillan, pp. 249260.

Ebashi, S. (1965) The sarcoplasmic reticulum and excitation-contraction coupling. In Molecular Biology of Muscular Contraction, ed. by Ebashi, S., Oosawa, F., SeKine, T., and Tonomura, Y. Igaku-shoin, Tokyo and Elsevier Publishing Co., Amsterdam, pp. 197206.

Ito, Y. and Kuriyama, H. (1971) Caffeine and excitation-contraction coupling in the guinea-pig taenia coli. J. Gen. Physiol., 57: 448-463.

Ito, Y. and KuriYama, H. (1974) Effects of thymol on the electrical and mechanical properties of the guinea-pig taenia coli. J. Physiol., 236: 143-157.

Ito, Y., Osa, T., and KuRIYAma, H. (1974) Topical differences of caffeine action on the smooth muscle cells of the guinea-pig alimentary canal. Jap. J. Physiol., 24: 217-232.

KuRIYAmA, H. (1970) Effects of ions and drugs on the electrical activity of smooth muscle. In Smooth Muscle, ed. by Bülbring, E., Brading, A., Jones, A., and Tomita, T. Edward Arnold, London., pp. 366-395.

OGAWA, Y. (1970) Some properties of fragmented frog sarcoplasmic reticulum with particular reference to its response to caffeine. J. Biochem., 67: 667-683. 